\title{
Factores empíricos en la conformación del canon literario
}

\author{
Alberto Montaner Frutos \\ Universidad de Zaragoza* \\ amonta@unizar.es
}

Fecha de recepción: 14/04/2011, Fecha de publicación: 25/04/2011

<URL: http://www.studiaaurea.com/articulo.php?id=195 >

\begin{abstract}
Resumen
El canon es en lo esencial una nómina de autores tradicionalmente aceptada. Su valor radica en el papel desempeñado en la propia historia literaria. Sin embargo, no puede ser aceptado de forma acrítica. Cuando es necesario aquilatarlo, puede ser útil recurrir a factores contrastables empíricamente que corrijan el sesgo del mismo en virtud de aspectos pertinentes para el estudio sociohistórico de la literatura. Las variables (algunas de ellas de tipo bibliométrico) que aquí se propone tener en cuenta son: la trascendencia histórica de su influjo, su grado de representatividad de las corrientes dominantes en un período dado, sus innovaciones estéticas, sus niveles de visibilidad e impacto coetáneos y su índice de productividad.
\end{abstract}

\section{Palabras clave}

Canon literario. Factores empíricos. Indicadores bibliométricos. Influjo histórico. Innovación estética. Visibilidad. Impacto. Productividad.

\begin{abstract}
Empirical factors in the making of a literary canon

The canon is essentially a traditionally accepted list of authors. Its value lies in its role in literary history itself. However, it cannot be accepted uncritically. When it is necessary to clarify it, it may be useful to employ empirically testable factors to correct its bias by using issues relevant to the socio-historical study of literature. Variables here proposed (including several bibliometric ones) are: the historical significance of an author's influence, how representative is an author of the literary movements of a given period, his or her aesthetic innovations, visibility and impact levels and rate of productivity.
\end{abstract}

* El presente trabajo se enmarca en las actividades del Proyecto del Plan Nacional de I+D+i del Ministerio de Ciencia e Innovación (con subvención de Fondos Feder) FFI2009-13058: FEHTYCH. Agradezco a Fernando Montaner sus aportaciones en la discusión téorica. 


\section{Key words}

Literary canon. Empirical factors. Bibliometric indicators. Historical influence. Aesthetic innovation. Visibility. Impact. Productivity.

Justificar la necesidad de seleccionar un elenco de autores no puede hacerse, a mi juicio, de forma absoluta, sino únicamente relativa a lo que, en términos económicos (que no economicistas) sería el problema de la limitación de los recursos y la consecuente exigencia de dar un orden de prioridad a las necesidades, algo que, en el campo de los estudios literarios, se manifiesta sobre todo cuando se trata de organizar una programación docente o de elaborar un compendio o epítome histórico-literario. Piénsese, por ejemplo en las contribuciones panorámicas de Uría (2000) sobre el mester de clerecía, de Rubio Cremades (2001) sobre la novela realista y naturalista en España o, con más razón (por lo que hace a los problemas aquí tratados), de Romero (1994) sobre el Romanticismo español. En tales casos, junto al papel de la síntesis, representado por los temas dedicados a movimientos y a géneros, se encuentra el del análisis, que obliga a realizar una selección de autores concretos para su incorporación a un repertorio o a un temario necesariamente restrictivos. Esta selección determinará no sólo la relación de escritores tratados, sino el tipo de atención que se les debe prestar, dado que no se les puede dedicar a todos el mismo espacio o tiempo. No se trata, pues, de una mera criba, sino de una inevitable jerarquización. Ésta queda en buena parte determinada por una nómina heredada, establecida en razón de criterios socioculturales posiblemente heterogéneos, pero no por ello menos eficaces al respecto, y que están vinculados a la institucionalización social de la literatura: «Hoy [...] pensamos que la historia de la literatura refleja los avatares de una institución (que tiene sus facetas lingüísticas, económicas, de control ideológico, de formación escolar...) y la cambiante constitución de un canon de escritores y tendencias, vivido como patrimonio propio de una comunidad. Y en tal sentido, la historia de la literatura cobra - como disciplina académica y como objeto de interés público— una nueva legitimidad». ${ }^{1}$

1. Alvar, Mainer y Navarro (1997: 11). Véase una exposición más detallada en Pozuelo Yvancos y Aradra Sánchez (2000), así como las reflexiones críticas (gnoseológicas y epistemológicas) de Maestro (2010: 37-43). Realizan también interesantes comentarios al respecto, partiendo de la evolución del canon hispánico en aspectos y casos concretos, Galván (2001), Romero (2006: 99-107 y 169-192) y Escobar (2007). 
Ahora bien, si la «canonización autorial» se asienta claramente sobre una base social e histórica que no puede en ningún caso desdeñarse, porque ha marcado tanto el devenir de los gustos literarios como el de los mecanismos sociales relacionados con la categoría sociocultural de literatura, es obvio que, por ello mismo, implica cierto componente parcialmente arbitrario. Por ello, aun partiendo ineludiblemente del canon establecido, a la hora de plantearse una programación o una síntesis histórico-literaria deben tenerse en cuenta otros factores, que permitan una reconsideración crítica de la nómina y jerarquía recibidas. Desde luego, ello no puede hacerse apelando al dudoso papel del juicio estético propugnado por algunos defensores de la teoría del canon, ${ }^{2}$ en especial Bloom (1995), quien defiende que éste es «una elección entre textos que compiten por sobrevivir», hecha "por autores de aparición posterior que se sienten elegidos por figuras anteriores concretas» (p. 30). Tal «elección estética» (p. 32) debe basarse en la «supremacía estética», que a su vez depende de "la suma de la extrañeza y la belleza» (p. 13), o bien se «irrumpe en el canon por la fuerza estética, que se compone primordialmente de la siguiente amalgama: dominio del lenguaje metafórico, originalidad, poder cognitivo, sabiduría y exuberancia en la dicción» (p. 39), y ello pese a reconocer que «el yo individual es el único método y el único criterio para percibir el valor estético» (p. 33). En cuanto a éste, aunque no se explica cómo, «es engendrado por una interacción entre los artistas, una influencia que es siempre una interpretación» (p. 34), con lo que volvemos al principio, en una sospechosa circularidad. La objeción fundamental a esta justificación "esteticista» es que el gusto, aunque no sea arbitrario, tampoco es objetivo. Fruto de pautas socioculturales (derivadas en parte de la existencia de sucesivos cánones artísticos) combinadas inextricablemente con circunstancias tan personales como intransferibles, el juicio estético es esencialmente subjetivo y aunque pueda explicarse históricamente, no puede fundamentarse ontológicamente, a menos que se participe del concepto eidético de Belleza, al modo platónico. Aun de aceptarse esta base metafísica, la filología, que es una disciplina fenoménica (o fenomenológica, en el sentido que se le da al término en Física), no podría dar cuenta de ella. Por supuesto, ello no significa prescindir del aspecto estético de la literatura como de algo inasequible, sino enfocarlo adecuadamente, separando la comprensión de esa dimensión estética del juicio sumarísimo destinado a incluir o excluir un determinado nombre del canon o a situarlo a una altura u otra del mismo, lo cual es, a mi juicio, improcedente en los estudios literarios (cf. Montaner, 2003: 312-315: y 2010: 200-207).

Ahora bien, justamente al no apelar directamente a una valoración estética, quedan abiertas otras posibilidades de reconsiderar el canon en términos que

2. Esta orientación es característica de los teóricos estadounidenses (cf. Pozuelo Yvancos y Aradra Sánchez, 2000: 33-61), pues otras teorías que han tratado del canon, como la de los polisistemas, se han preocupado más bien de cómo surge éste y apuntan, por el contrario, hacia consideraciones historicistas más cercanas al planteamiento aquí defendido (Pozuelo Yvancos y Aradra Sánchez, 2000: 77-120). 
resulten de algún modo ponderables, incluso si no resultan siempre estrictamente cuantificables. Dicho en otros términos, a factores empíricos distintos del mero aluvión histórico, potencialmente amorfo, o del subjetivo criterio del gusto, del cual, como reza la vieja y sabia máxima, non est disputandum. En este sentido, y aunque no comparta su caracterización específica del «ámbito de actuación LITERATURA» como un tipo especial de comunicación, ${ }^{3}$ considero que Schmidt (1991) acierta plenamente al plantear que «las declaraciones de la teoría [literaria] deben ser empíricamente comprobables y hacer referencia al ámbito de actuación social "literatura"» (p. 17) y que "la investigación científico-literaria debe salir del rincón de las llamadas ciencias del espíritu que le fue asignado desde W. Dilthey hasta J. Habermas y necesita una base teóricocientífica explícita y adecuada a sus intereses de investigación» (p. 29), lo que se consigue, entre otras cosas, en virtud del postulado de comprobabilidad: "sus problemas y resultados [...] son comprobables intersubjetivamente, es decir, están formulados sobre una base empírica y con la ayuda de argumentos que no contradicen los fundamentos de la lógica formal» (p. 31). Sin embargo, dicho autor no explica de qué forma(s) pueden contrastarse las hipótesis con el registro factual (o base empírica); es decir, se mantiene eminentemente en el plano teorético, sin descender a su engarce metodológico con los datos con los que tales hipótesis habrían de contrastarse. Por mi parte, considerando que algunos de los factores capaces de influir en la conformación del canon son susceptibles de cuantificación, me valdré de algunos postulados de la bibliometría, en su concepción prístina de modelo matemático destinado a formalizar algunos fenómenos estudiados en el ámbito de la historia y la sociología de la ciencia, ${ }^{4}$ y no, desde luego, como técnica sustitutiva del análisis cualitativo en el ámbito de la evaluación de la producción científica (mediante factores, generalmente mal calculados y empleados, como los índices de impacto y de citas), aplicación aberrante, hoy generalizada por las diversas y solapadas agencias de (presunta) evaluación de la calidad científica, pero que los propios fundadores de la disci-

3. Según lo había anticipado ya Mukařovský (1977: 317), al señalar que «En este lenguaje [el poético] la actualización adquiere a veces una máxima intensidad, de tal modo que eclipsa la comunicación en tanto que finalidad de la expresión y se convierte en algo que tiene la finalidad en sí mismo; su objetivo no es el de servir a la comunicación, sino el de destacar en primer plano el propio acto de expresión». No obstante, la manera en que el semiótico checo justifica esta relegación de lo comunicativo, mediante el concepto de desautomatización, como opuesto al de actualización, no resulta convincente, dado que exige un tipo de lectura crítica o, de otro modo, rupturista que no es generalizable al conjunto de la recepción literaria.

4. Véase un interesante ejemplo consagrado a la propia Filología Española en Urbano et al. (2005), quienes, sin embargo, incurren en el error metodológico de mezclar criterios descriptivos con juicios de valor, del tipo «se ha de considerar un signo de normalidad y de calidad en el currículum de un investigador de estas áreas la presencia de publicaciones de ambas categorías» (p. 444, el subrayado es mío), es decir, tanto de monografías como de artículos en publicaciones periódicas de tipo científico o académico. 
plina denunciaron en su momento (cf. Callon, Courtial y Penan, 1993: 47, y Katz 1999: 1-2).

Antes de desarrollar los aspectos en los que parece posible aplicar ciertos criterios empíricos como modo de selección y jerarquización de los autores (en términos puramente históricos y no de valor, como queda dicho), es preciso hacer una consideración previa sobre lo que cabría denominar un factor correctivo anterior a dicha tarea. En general, un canon no se establece en términos puramente individuales, es decir, relativo a los autores considerados de forma exenta, sino que se relaciona igualmente con el que antes he denominado plano de la síntesis y singularmente aparece subordinado a la periodización. Aunque no voy a entrar a cuestionar este peliagudo aspecto, he de señalar que, al margen de la validez de divisiones concretas y siempre teniendo en cuenta que rara vez se producen transformaciones bruscas, por lo que hay que tener en cuenta fases de transición, la distinción de (que no compartimentación en) períodos me parece una operación legítima en la historia cultural. ${ }^{5}$ De todos modos, a los efectos más pragmáticos de los que aquí me ocupo, basta constatar la relación que se establece (pero no de modo homogéneo) entre periodización y determinación del canon. En el caso de las divisiones consagradas en la historiografía de la literatura española y susceptibles de traducirse en los manuales o programas docentes correspondientes, a saber, Edad Media (siglos XI-Xv), Siglo o Edad de Oro (siglos XVI y XVII) y Edad Contemporánea (siglos XVIII, XIX y XX, al que sirve de apéndice, en su caso, lo que llevamos del xxI), ${ }^{6}$ conviene plantearse una cuestión conexa: la de la extensión que, en número de temas o lecciones, debe tener cada una de dichas etapas, dado que a su vez ello repercutirá en la selección y tipo de atención de que serán objeto los autores correspondientes a cada una de las mismas.

Habida cuenta de su duración, resultaría lógico dedicar a todas una extensión semejante, salvo a la primera, que debería ser más amplia, por abarcar más tiempo. Esto resulta razonable, siempre que no se aplique de un modo proporcional, pues entonces a la Edad Media debería consagrarse más de un tercio de los temarios o programas. El otro parámetro que habría de considerarse es

5. Véanse los fundamentos, aunque también las limitaciones, de la periodización histórica en Frutos (1991: 373-389). Para la discusión del concepto mismo de período literario, puede verse además Guillén (1989: 119-138).

6. Susceptibles de dividirse, en propuestas más detalladas, en Edad Media (subdivisible a su vez en Plena y Baja Edad Media, aunque es criterio que no suele aplicarse), Renacimiento, Barroco, Ilustración-Neoclasicismo, Romanticismo-Realismo, Modernismo-Vanguardia y el aún más obvio cajón de sastre de la Guerra y Postguerra. En la práctica, especialmente de la planificación docente, se ha solido recurrir a una cómoda, pero problemática (aunque no completamente arbitraria) división secular, a asignatura por siglo, salvo en el caso medieval, si bien la implantación de la reforma a la bolońesa está llevando a la consagración de modelos alternativos, aún de resultado incierto. Para una panorámica crítica de esta división, véanse Tacca (1985) y Mainer (1993), así como las reflexiones de Romero (2006: 29-34). 
el de la producción propia de cada período. En ese sentido, resulta claro que la citada época posee una menor densidad, al menos en obras conservadas, lo que actuará de factor de corrección a la hora de aplicar el criterio cronológico antedicho. ${ }^{7}$ De cualquier forma, las bibliografías no son aún lo suficientemente completas como para establecer una cuantificación ajustada de cada período, lo que impide aplicar estrictamente este criterio. Por otra parte, éste no constituye por sí solo un parámetro realmente adecuado, si lo que se pretende es dar una visión de conjunto, dado que en ella se efectúa una selección y el número total de obras y autores comentados no suele diferir significativamente de una etapa a otra, al menos a tenor de los programas docentes a los que he tenido acceso a lo largo de mi carrera profesional. Pese a ello, la práctica manualística ha tendido a cierto desequilibrio en su reparto por temas. Sirvan de punto de referencia las representativas obras coordinadas por Jones (1973-1984), Rico (1980-1992), Ferreras (1987-1992), Canavaggio (1994-1995) y, aún en curso de publicación, Mainer (2010-2011). Su distribución en términos de extensión temática puede advertirse en el siguiente gráfico: ${ }^{8}$

7. El importante papel de la oralidad en el Medioevo, así como la mayor dificultad para la elaboración de ejemplares, dada la carestía de los materiales de escritorio y la lentitud del proceso de copia, han hecho que se pierda una parte no desdeñable de las obras del período, por lo que la relativa escasez de textos literarios en comparación con las épocas posteriores no se debe únicamente a una menor producción de los mismos. Véanse al respecto el trabajo pionero de Deyermond (1976-1977), su expansión (lamentablemente inconclusa) en Deyermond (1995) y las explicaciones sugeridas por Smith (1984). No obstante, los progresos de la investigación van haciendo aflorar constantemente obras nuevas, perdidas en archivos y bibliotecas o que simplemente habían pasado desapercibidas (cf. Montaner, 2005). Especialmente, el ámbito de la prosa se ha visto notablemente enriquecido en las últimas décadas, como puede advertirse en el monumental compendio de Gómez Redondo (1998-2007). En conjunto, puede verse también Alvar y Lucía (2002).

8. Los porcentajes se han calculado partiendo de la extensión en páginas dedicada a cada pe- ríodo. He de advertir que he prescindido de los suplementos en el caso de la obra dirigida por Rico, así como de los vols. XXVII-XXXVI de la serie coordinada por Ferreras, por caer fuera del ámbito específico de la literatura española. En cuanto a la obra dirigida por Jones, he repartido en dos mitades la extensión dedicada conjuntamente a la Edad de Oro, para facilitar la comparación. Además debe tenerse en cuenta que la edición original inglesa (Jones, 19711972) carecía del tomo 6/2: Literatura actual, añadido en la versión española. Por otra parte, dado que la serie de Ferreras quedó inconclusa (pues no vieron la luz cuatro de los veintiséis volúmenes indicados), para poder ofrecer una cuantificación lo menos desviada posible, he asignado a cada volumen faltante la media aritmética de la extensión de los demás correspondientes al mismo período. En cuanto a la obra coordinada por Mainer, quedan tres volúmenes por publicar, a los que he atribuido, para hacer una aproximación, la media de páginas calculada a partir de los vols. III, V y VI, puesto que el VII (con 1216 pp.) se desvía demasiado del promedio. 


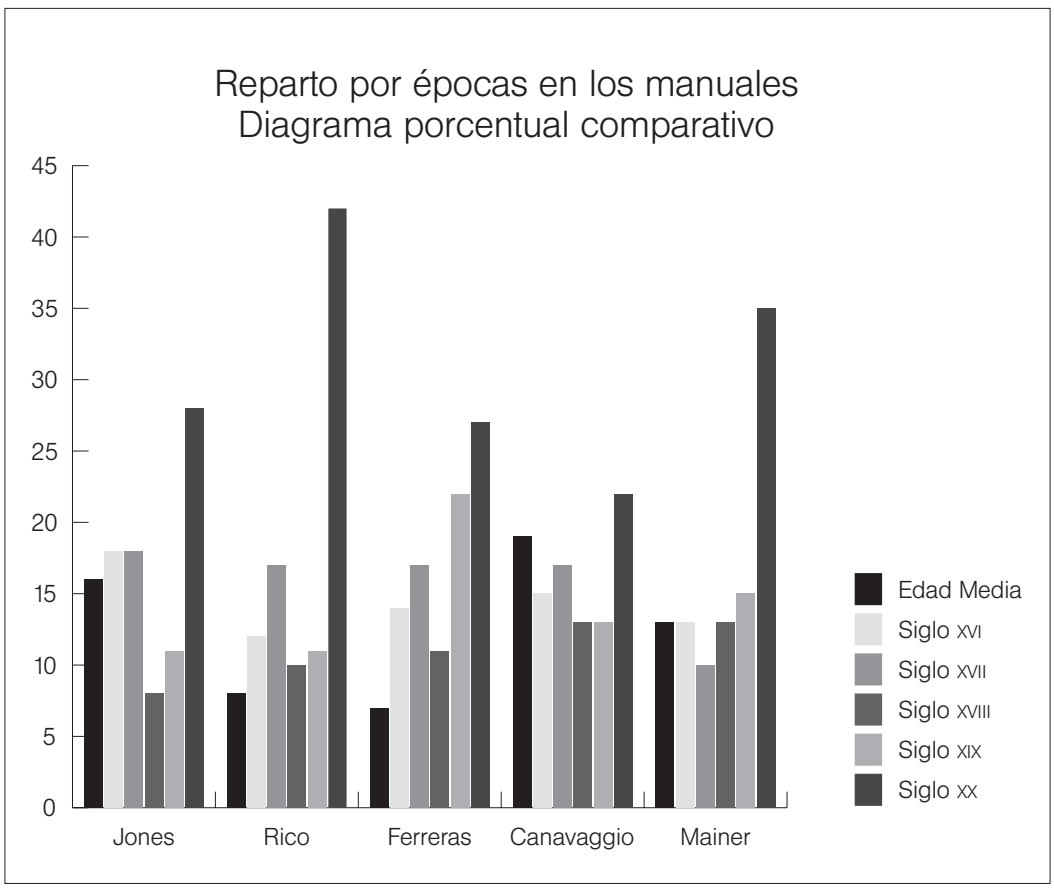

Según se puede apreciar, existe un marcado desnivel en la mayoría de estas obras, que conducen a una mayor o menor hipertrofia de la etapa actual, mientras que otras épocas, singularmente la Edad Media y el siglo xviII, quedan en franca desventaja. No creo que tal irregularidad en la distribución quede suficientemente justificada en términos de relevancia cultural de la producción reciente respecto del total de la historia literaria española, por más que el período que abarca desde finales del siglo XIX al segundo tercio del siglo Xx constituya, en expresión justamente consagrada, la Edad de Plata de nuestras letras. ${ }^{9}$

9. Para la génesis y alcance de esta designación, véase Mainer (1983: 11-16). En todo caso, parece obvio que la fragmentación de la actividad literaria más cercana en múltiples corrientes falsea un tanto la percepción de la literatura contemporánea, que la historiografía futura tenderá sin duda a reducir, al ganar en perspectiva de conjunto. Nótese a este respecto que la diferencia que media entre el teatro de Lucas Fernández y el de Juan de la Cueva supera con mucho la que pueda ofrecerse entre Un drama nuevo de Tamayo y la Historia de una escalera de Buero, en términos de constitución escénica, estructura dramática y elementos específicos de la teatralidad. En este sentido, parece probable que, a la larga, todo el período que va desde el modernismo (e incluso desde sus raíces becquerianas) a la postmodernidad, incluida la ruptura, a menudo más aparente que real, de las vanguardias, pueda llegar a subsumirse en un sólo movimiento de conjunto, aunque distinguiendo diversas fases o variedades internas, como las que pueden darse dentro del mester de clerecía o de la poesía barroca. Apuntaba ya en esta línea Gullón (1969: 
Incluso si se pudiera demostrar que en el ámbito literario se cumple el aserto realizado por la sociología de la ciencia respecto de la comunidad científica, a saber, que en la actualidad está vivo casi el noventa por ciento de todos los investigadores que en el mundo han sido, ${ }^{10}$ esto no podría justificar tales desequilibrios. En efecto, la diferente significación histórica de cada etapa respecto del conjunto de la historia literaria espańola, en caso de que la misma pudiera realmente baremarse, no bastaría para apoyar una desigualdad llevada a esos extremos, porque el enfoque historiográfico debe conjugar armónicamente el discurrir diacrónico con los cortes sincrónicos, y éstos, en sí, precisan de similares recursos explicativos, cuya exposición requiere una cantidad semejante de espacio o de tiempo. ${ }^{11}$

Tampoco puede, a mi juicio, ampararse dicha postura en los desequilibrios de la propia investigación literaria, que se ha orientado con mayor dedicación a la literatura contemporánea. ${ }^{12}$ En efecto, este factor será determinante en un repertorio bibliográfico y quizá incluso sea adecuado en un estado de la cuestión con antología crítica, como es la obra coordinada por Rico, pero no parece adecuado en un manual, temario o programa que pretenda atenerse a las obras en sí y no a un mero balance de la investigación realizada. Sin embargo, tampoco postulo que sea preciso un reparto igualita-

9-12) y ha vuelto sobre la cuestión Mainer en sus notas a la edición revisada de Brown (1983: 35). 10. Se trata del «principio de contemporaneidad» de la ciencia, que tiene su base en la «ley» del crecimiento exponencial de la misma; vid. Terrada y Peris (1988: 14) y cf. Coll-Vinent y Bernal (1990: 19-21). La extrapolación de este dato al ámbito literario resulta sumamente arriesgada si se tiene en cuenta que la investigación científica depende en alta medida de la infraestructura disponible y que la «ley» del aumento exponencial de la comunidad científica exige que la inversión en equipamiento responda a la misma pauta. En cambio, la actividad literaria no requiere, en el caso extremo, más que la propia memoria para llevarse a cabo. Si a esto se añade que en diversas épocas la creación literaria ha sido una actividad social de buen tono (recuérdese la poesía cortesana del siglo xv o los poemas de álbum y abanico en el siglo XIX), lo que no es hoy el caso, se comprenderá que la actual proliferación de textos literarios no supera necesariamente (salvo quizá en el número de publicaciones) las cotas de épocas pretéritas, al menos en relación al total de la población existente (es decir, en términos de "escritores per cápita»).
Es posible, no obstante, que la creciente «cultura de blog» haga variar esta percepción, pero (incluso sin entrar a discutir qué parte de esa producción puede considerarse literaria), esto no cambiaría la cuestión de fondo.

11. Aquí es de aplicación lo que de un modo más general señala Frutos (1991: 336-387): «Cierto que la perspectiva temporal de la historia resulta falseada, aun partiendo del punto de vista del presente. Este punto de vista exige que los tiempos más cercanos, situados en primer término, se vean mayores que los lejanos. Pero esta diferencia, naturalmente exigida, y con la que se supera la pura objetividad sintetizándola con el observador, no permite la distancia enorme que el cuadro tradicional de las edades presenta entre la brevedad con la que se habla de la edad antigua y la extensión de las otras tres. [...] Insisto en que la extensión material puede, y aun debe, ser mayor en las edades más ricamente conocidas, pero salvando siempre la extensión temporal que realmente les corresponde».

12. Entendiendo aquí el adjetivo según su uso como etapa histórica, es decir, desde la Revolución Francesa en adelante. Cf. las observaciones preliminares de Mainer (1980: XXII). 
rio de los temarios entre sus secciones mayores, sino uno equitativo, basado en los parámetros de duración, nivel de producción literaria y (hasta donde sea posible determinarla) importancia relativa dentro del conjunto histórico. Por todo ello, resulta conveniente mantener una proporción adecuada entre las distintas secciones destinadas a las grandes etapas de la evolución literaria espańola, que, teniendo en cuenta los principios expuestos, podría plasmarse, aunque de forma meramente orientativa, en el siguiente diagrama, basado en las anteriores reflexiones, combinadas con mi propia experiencia docente y que se acerca bastante al reparto adoptado por Canavaggio (1994-1995), aunque corrigiendo su leve escora hacia el siglo xx:

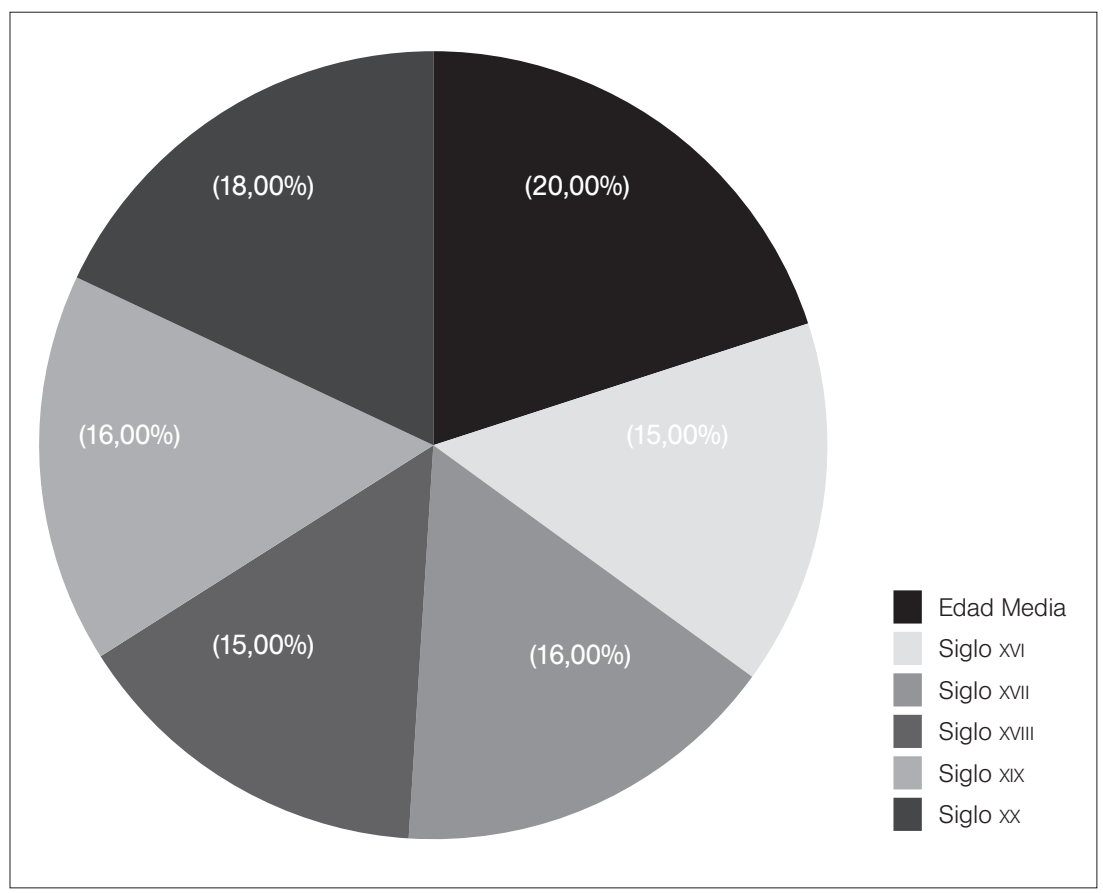

Solventada, espero, esta cuestión previa, cuya resolución anula en cierto modo la interferencia de la periodización respecto de las restricciones selectivas en la nómina de autores y obras, podemos centrarnos en los aspectos concretos del canon histórico-literario. En un enfoque diacrónico, uno de los factores que sin duda resulta primordial es la importancia relativa en la evolución (que no progreso) del sistema literario. A este respecto, resulta ilustrativa la clasificación de Doležel (1969: 14-19), que divide a los autores en context-free writers o autores originales que se sitúan al margen del contexto, context-sensitive writers o autores sensibles al contexto, en el cual se incardinan como parte de una corriente, y context-bound 
writers o autores totalmente dependientes del contexto, los epígonos. ${ }^{13}$ Habida cuenta de que es materialmente imposible sustraerse al influjo del contexto literario, tanto como del social, cabría reinterpretar la primera categoría adscribiéndole los autores cuya incardinación en un contexto no les impide transformarlo. Estos últimos son los que, en términos de la teoría de la recepción, amplían el horizonte de expectativas de su época. Metafóricamente, podría decirse que los otros dos grados corresponden respectivamente a quienes llegan al límite de ese horizonte y, en fin, a aquellos que ni siquiera lo alcanzan. En términos más precisos, los primeros son los que imponen sus propias normas estéticas (llegando incluso a ocasionar un cambio de sistema); los segundos, quienes se acogen a las vigentes, pero elaborándolas de un modo individualizado y los terceros, los que se atienen a aquéllas sin apenas desviación, especialmente cuando siguen fieles a las mismas, pese a que las de un nuevo sistema ya les hacen la competencia.

Ahora bien, este enfoque no agota las posibilidades del análisis diacrónico, entre otras cosas, porque la actitud personal puede no alcanzar traducción colectiva y, por lo tanto, no llegar a trascender. Así, un autor del segundo grupo e incluso alguno del tercero ha podido en ocasiones producir una influencia dilatada que haya hecho su obra más importante para la evolución literaria que las novedosas aportaciones de uno del primero. Por lo demás, esto no es arbitrario; sólo en tiempos recientes se ha valorado la originalidad como el bien supremo de la creación artística, por lo que determinado equilibrio entre novedad y tradición ha sido habitualmente la mejor patente de inmortal fama, que diría Gracián, a lo largo de la historia literaria. Aunque expresada a otro propósito, es perfectamente aplicable aquí la reflexión de Pániker (2006: 13): «Y, más adelante, [vendrán] los autores retroprogresivos (la palabra es mía) para conciliar el discurso del yo con la sabiduría arcaica. Lo que ocurre, pienso, es que todo gran autor es retroprogresivo - concilia la innovación con la tradición-, y que los sucesivos períodos de la música (occidental) suelen conservar los hallazgos de las épocas anteriores». Pasando del ámbito musical al literario, puede señalarse con Blecua y Rico (2006: Ix), que: «Una historiografía literaria que ignore que los poetas [...] sustentan sus cuerpos con el pan de cada día y viven en un momento histórico concreto, no pasará de ser, aunque útil, una historiografía incompleta. Pero una historiografía que descuide la tradición literaria nunca podrá explicar en su totalidad el cambio literario[,] porque quien desconoce la tradición desconoce la originalidad».

13. Como aclara Lázaro Carreter (1976: 39), comentando esta propuesta, contexto se toma aquí en el específico sentido de "conjunto de factores objetivos que condicionan la elección verbal», lo que se vincula a las normas estéticas en vigor en un período dado. La clasificación sería igualmente válida si se entiende contexto de forma más genérica como 'marco del discurso', es decir, «entorno físico o de situación, ya sea político, histórico, cultural o de cualquier otra índole, en el cual se considera un hecho" (según la acepción segunda del DRAE; cf. Vega y Olmos, 2011: 134-136), pero entonces se referiría a posturas socio-culturales y no específicamente literarias. 
De hecho, a efectos de entender la historia literaria, resulta especialmente oportuno recordar aquí el aforismo de Wagensberg (2006: 47, \$ 172): «El secreto del cambio está en la parte del cambio que no cambia». Claro que el problema es, entonces, explicar la variabilidad, lo que, ineludiblemente, pasa por analizar el modo de adquisición de una norma estética. Esto nos remite al llamado «problema de Platón», el cual "consiste en explicar cómo conocemos tanto teniendo en cuenta que los datos de los que disponemos son tan escasos» (Chomsky, 1989: 11). En otras palabras, qué es lo que permite a la mente humana inferir a partir de una serie limitada de datos el mecanismo general que gobierna una actividad o un fenómeno, no de un modo consciente, sino mediante capacidades mentales específicas, a la manera en la que un niño aprende su lengua materna. Como sucede en el caso del lenguaje, esta inferencia no tiene por qué realizarse de modo consciente, ya que no se manifiesta en la capacidad de explicitar las reglas subyacentes, sino en la competencia para emitir y reconocer enunciados. De todos modos, no es necesario suponer que este procedimiento de tipo inductivo actúe siempre del mismo modo que en la adquisición del lenguaje; basta con establecer el hecho fundamental de que la captación estética tiene en él su base y que, por tanto, constituye el modo en que se efectúa el tipo de aprendizaje al que estoy aludiendo. En el caso de la obra de arte y en particular la literaria, tales capacidades se aplican a la captación de una norma estética extrayendo sus rasgos mediante la percepción de un conjunto de regularidades en una serie de obras que lo comparten. Esto se produce, usualmente, a partir de escasas muestras, cuyas regularidades no podrían extraerse, por ejemplo, de un mero análisis computacional. Piénsese en la facilidad con que a un aprendiz de poeta le salen pastiches de sus autores favoritos, con sólo haber leído una selección de sus poemas. Esto es, de hecho, lo que hacía viable el método humanístico de la imitatio auctorum como forma de aprendizaje artístico. De aquí se deduce claramente que, contra lo que opinan autores como Fish (1973-1974) o Di Girolamo (1982: 91-92), el establecimiento de los rasgos que integran una norma estética no refleja una decisión colectiva sobre lo que debe ser considerado literatura, porque en éste, como en casi ningún otro aspecto de la cultura, no funcionan ni el mito rousseauniano del contrato social ni el postmoderno de la negociación. En consecuencia, las causas del cambio de las normas estéticas tampoco responden a un consenso explícito de creadores y público.

Podría pensarse, entonces, que una norma estética llega a imponerse por dos vías. Una sería la ya aludida, es decir, la creación por context-free writers de una o varias obras que incorporen propuestas distintas a las de la norma vigente, lo que la teoría de la recepción ha llamado la ruptura del horizonte de expectativas, de forma que el lector capte y, en su caso, acepte las innovaciones allí plasmadas. La otra consistiría en la realización de una propuesta explícita de cambio estético, a través de un texto programático, lo que podría ejemplificarse desde la preceptiva neoaristotélica del Renacimiento hasta los manifiestos de toda índole redactados a lo largo del siglo xx a partir del período vanguardista de entreguerras. Ahora bien, si la primera posibilidad se desprende lógicamente del proceso mismo de aprendi- 
zaje de una norma estética, la segunda resulta, si se considera con atención, menos obvia de lo que parece. Piénsese, por ejemplo, en el programa surrealista y en una de las producciones paradigmáticas de este movimiento, como es la película de Buñuel y Dalí Un chien andalou. No cabe duda de que el espectador del filme identificará como tal el carácter onírico que aquél transmite. Sin embargo, le resultará inevitablemente más cercano a la herencia cinematográfica previa que a sus propios sueños. La razón de ello es doble; ante todo, la carga emotiva de los sueños, que es estrictamente individual, resulta casi imposible de transferir. Además, la plasmación fílmica de este tipo de escenas, como la de cualquier otro, está completamente mediatizada por el lenguaje del cine. Este caso avalaría, pues, la tesis de que la introducción de nuevas normas estéticas no se realiza por medio de propuestas programáticas. Sin embargo, contra esto se podría aducir que nos hallamos ante una manifestación concreta del surrealismo cuya falta de acuerdo con su programa sobre lo que debe ser el arte es circunstancial, lo que no impediría la existencia de otras obras que sí lo cumplieran. No obstante, la segunda razón aducida, es decir, la dependencia de los recursos cinematográficos vigentes, hace ver las limitaciones de ésta como de cualquier preceptiva. De hecho, la misma doble objeción puede hacerse extensiva al resto de las manifestaciones del surrealismo. Así, su pintura debe indudablemente más a determinada interpretación del Bosco que al auténtico lenguaje onírico, del mismo modo que su poesía tiene más deudas con ciertos experimentos formales de Mallarmé, por no citar las vanguardias inmediatamente precedentes, que con las verdaderas expresiones del inconsciente.

Por lo tanto, puede postularse que todo autor que se halle en la tesitura de llevar a la práctica un programa literario dado se encontrará con que tiene que colmar de algún modo los huecos del mismo. Esto no sólo supone una interpretación personal de tal propuesta, sino que, en determinadas ocasiones, puede conducir a entrar en contradicción con ella y, así, modificarla. Brinda un buen ejemplo de esto el caso de la tragedia renacentista española. ${ }^{14}$ Sus autores (Jerónimo Bermúdez y Cristóbal de Virués, en una primera etapa, y Andrés Rey de Artieda, Lupercio Leonardo de Argensola o el propio Cervantes, en una segunda) pretendían guiarse por los tratadistas coetáneos que postulaban como norma, al hilo de Horacio, las reflexiones aristotélicas sobre el género. Pero como (según queda dicho) a escribir se aprende leyendo, tuvieron que buscarse algún modelo concreto que les sirviese de pauta, a falta de genuinas tragedias aristotélicas en las que inspirarse, pues éstas nunca habían existido, como tampoco los animales de la época helenística se

14. Reduzco a sus líneas esenciales el problema (sobre el que agradezco las agudas y sabias observaciones de María José Vega), sobre el cual pueden verse Hermenegildo (1973) y el volumen colectivo coordinado por el Grupo de Estudios Sobre Teatro Español (1983). Respecto de la recepción hispana de la preceptiva aristotélica, cf. Sánchez Escribano y Porqueras Mayo (1971, esp. pp. 46-49). La influencia de la obra trágica de Séneca en la dramaturgia renacentista es brevemente analizada en el estudio sobre el senequismo español de Blüher (1983). 
guiaban por la zoología del Estagirita. Salvo en el caso de Fernán Pérez de Oliva, que, además de escribir en un momento previo a la difusión del modelo neoaristotélico, revela un contacto directo con obras que, al menos, inspiraron la Poética (en especial, las de Sófocles y Eurípides), los restantes trágicos españoles fueron a elegir, en parte por razones de accesibilidad y en parte por buscar un compromiso con los gustos del público, las tragedias de Séneca, las cuales habían inspirado ya a los trágicos italianos del momento (si bien el humanismo temprano había manifestado su preferencia por Eurípides, traducido, por ejemplo, por Erasmo, pero que luego quedaría postergado en el medio neoaristotélico).

El caso es que la imitación del cordobés alteraba inevitablemente la preceptiva a la que dichos autores pretendían acogerse, entre otras causas porque les llevó a desplazar el acento, de la catarsis espiritual propugnada por Aristóteles a partir de las ineluctables fuerzas del destino (algo, por otra parte, difícilmente compatible con la doctrina cristiana y que había turbado ya a ciertos tratadistas italianos, como se advierte en las anotaciones de Robortello a la Poética), a cierto tremendismo truculento con un sesgo neoestoico de implicaciones marcadamente políticas. ${ }^{15}$ La conclusión a la que llevan estos ejemplos es que, en efecto, no hay rupturas absolutas en el ámbito de la evolución literaria, puesto que toda nueva propuesta debe basarse necesariamente, aunque de modos diversos, en las preexistentes y ni siquiera una voluntad programática explícita es capaz de evitarlo, de modo que la originalidad absoluta es, sencillamente, un imposible ontológico. A parte de otras importantes implicaciones, a los presentes efectos esto supone que el influjo ejercido por un autor es un factor ponderable en sí mismo y no necesariamente correlativo de su originalidad, aunque, lógicamente, cuando ambos elementos coincidan, la huella de un autor o de determinada obra suya habrá sido mucho más profunda y duradera.

Ahora bien, es obvio que el sistema literario no actúa sólo en diacronía, sino también y ante todo en sincronía. Esto obliga a tener en cuenta otros parámetros distintos de la trascendencia evolutiva de un autor. Uno de ellos es el éxito de público, aspecto tantas veces desdeñado por la historiografía literaria tradicional y más aún por la crítica literaria de actualidad, pero sin el que es incomprensible una determinada situación histórica. Ese éxito no siempre se ha correspondido a la influencia ejercida posteriormente por ese autor, pues no es lo mismo la capacidad de captación de la audiencia que la de modificar el sistema de valores literario. Cuando ambos fenómenos se conjugan, como ocurre con Lope de Vega, no suele haber du-

15. Precisamente, la mixtura de la preceptiva neoaristotélica, el patrón senequista, el influjo del teatro español coetáneo y ciertas innovaciones personales dio como precipitado algunas de las novedades que cristalizarían en la comedia nueva. Véanse a este propósito, para los trágicos valencianos, Sirera (1981) y (1986), y respecto de Juan de la Cueva, además del clásico trabajo de Wardropper (1955), la revisión que hace de su papel en la evolución dramática renacentista Sito Alba (1984). Sobre la influencia de Virués en el primer Lope, véase Rey Hazas (1995). 
das al respecto. Pero cuando sólo se da el primero, se ha tendido a postergar al autor en cuestión, creando una arbitraria relación inversa entre éxito y calidad intrínseca, o dicho en términos más precisos, entre la apreciación de la mayoría del público y el rechazo de una minoría de (pseudo)intelectuales que se ha arrogado, desde la cátedra o la tribuna periodística, la capacidad de expedir ejecutorias de literariedad. Al margen de la intrínseca arbitrariedad del procedimiento (denunciada hace tiempo de forma inmisericorde por Moreno, 1994), se da aquí un problema conceptual de mayor calado, desde el punto de vista de la propia historiografía literaria, toda vez que la transformación no es la única modalidad de afectar a la norma estética. La otra es básicamente la de consolidarla, y eso es lo que suele suceder con tales escritores, sin cuyo estudio es imposible reconstruir el estado de cosas en un momento dado de la historia de la literatura y mucho menos entenderlo. ${ }^{16}$

Algo parecido puede decirse, aunque quizá sin revestir tanta importancia, de la productividad de los autores. Por supuesto, la trascendencia histórica de un autor no guarda relación con ella y más de un escritor se ha consagrado por una sola obra, incluso siendo autor de varias. Sin embargo, la perspectiva sincrónica, al menos a medio plazo, sí que gana en claridad si se tiene en cuenta la existencia de autores prolíficos, que llenan una época con sus escritos, de forma que incluso sin obtener además una gran difusión, llegan a marcar en cierto modo la etapa en la que han vivido. En este ámbito, y frente a lo comentado sobre la ley de crecimiento exponencial, es bastante probable que en el ámbito literario se cumpla otro postulado bibliométrico, la denominada ley de Lotka. ${ }^{17}$ Según ésta, la productividad de los autores no responde a una distribución normal (que estaría representada por una campana de Gauss), sino a una específica, dado que en un dominio dado, coexisten un pequeño núcleo de autores muy productivos y una masa de autores que lo son mucho menos, de modo que el número de autores que publican una cifra de $n$ trabajos es inversamente proporcional a $n^{2}$, o, en sus propias palabras, "the number [of authors] making $n$ contributions is about $1 / n^{2}$ of those making one» (Lotka, 1926: 323). En una formulación más estricta, la relación entre el número de autores en activo $(y)$ y la cantidad de obras que produce cada uno $(x)$ se rige por la función $y=k / x^{2}$, donde $k$ es una constante cuyo valor es $k=0,6079 T$, siendo $T$ el número total de autores.

16. Ya llamaron la atención sobre este problema y otros relacionados Whinnom (1967) y Rodríguez Moñino (1968). Posteriormente, Jammes (1991) volvió a subrayar la importancia de estudiar a todos los autores considerados menores, como exponentes de la realidad literaria de un período. Véase además, esperemos que en un futuro cercano, el volumen colectivo basado en las reflexiones de Whinnom y coordinado por Deyermond (en prensa, desde 2006).

17. Esta «ley» bibliométrica fue enunciada y de- mostrada por Lotka (1926), y es recogida también por Terrada y Peris (1988: 19-20), Egghe y Rousseau (1990: 292-293), Callon, Courtial y Penan (1993: 42-44) y Maltrás (2003: 141144). Puede verse una excelente exposición teórico-práctica en PPT accesible en línea por Ruiz Baños (consultada el 10 de abril de 2011). Me hace pensar en su aplicabilidad al ámbito literario el haberla visto cumplida en un caso conexo, el de los recitadores modernos de romances de tradición oral (Montaner, 1989: 190). 


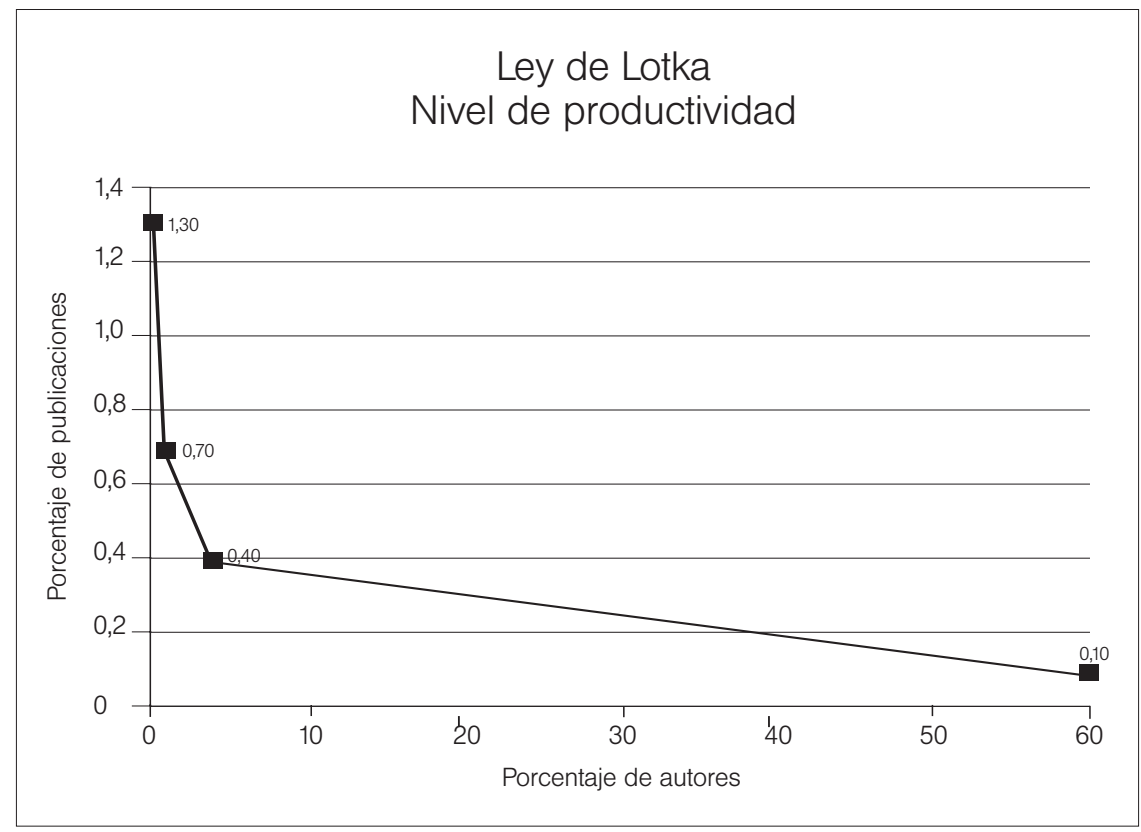

En términos generales, la ley de Lotka significa que, en el nivel de menor productividad, el $60 \%$ de los autores contribuye individualmente con la milésima parte de la producción, mientras que en el nivel máximo, el 0,3\% lo hace con algo más de la centésima parte. Ciertamente, el nivel de productividad no es un índice estricto del influjo ejercido por un autor sobre sus coetáneos, pero sí queda claro que, a igual difusión de cada obra, un elevado nivel de productividad implica un mayor impacto sobre el contexto. De este modo, se comprende que, incluso sin llevar aparejado un amplio éxito de público, un autor prolífico se dejará sentir suficientemente en el conjunto de la producción de una época.

Esta doble perspectiva de la capacidad de influencia de un autor en sincronía puede, por último, beneficiarse de la adecuada extrapolación de un concepto semejante al empleado en bibliometría para diferenciar la producción de un autor de su grado de influjo (o al menos de su nivel de recepción) en la comunidad científica, que se expresa mediante los índices de impacto y de visibilidad. ${ }^{18}$ Obviamente, no puede hacerse una aplicación directa de estas medidas a los

18. Estrictamente, impacto y visibilidad, aunque muy relacionados, son dos elementos independientes: «D'un article cité on peut faire l'hypothèse: a) qu'il est sufisamment visible pour qu'un chercheur juge nécessaire d'y faire référence; b) qu'il produit un impact sur la production des connaissances [...]. Compter le nombre des citations reçues par un article, c'est donc apprécier tout à la fois sa visibilité et son impact, et non point mesurer sa qualité» 
estudios literarios, pero tales categorías pueden adaptarse, creo que útilmente, tomando en cuenta dos factores. Uno es de cuantificación relativamente sencilla (aunque en la práctica no siempre viable, por lo laboriosa): la difusión de su obra, que a su vez puede medirse directamente por el número de las ediciones y la tirada de las mismas (o la frecuencia y duración de sus representaciones, en el caso del teatro), e indirectamente por la frecuencia con que se cita o parafrasea a un autor por parte de sus contemporáneos. ${ }^{19} \mathrm{El}$ otro resulta de mensuración más compleja, pues se trata del prestigio del que goza un autor en un momento dado, lo que sin duda condiciona su «impacto» sobre el cuerpo social, incluso independientemente del número de citas que se hagan de su obra o de la cantidad de sus publicaciones. Ambos índices, de visibilidad e impacto, serán obviamente altos si se toman en consideración autores a la vez muy leídos y afamados, que son los que solemos clasificar como "de primera fila», y de nuevo la figura del Fénix viene a las mientes de forma espontánea. En el caso de escritores poco divulgados, pero muy apreciados en ciertos círculos, obtendríamos una menor visibilidad, pero con un marcado impacto (al menos en determinadas sectores), lo que viene a corresponder a los autores «de culto». Finalmente, habrá otros «de consumo", cuya presencia en determinados medios (piénsese, para la literatura contemporánea, en el periodismo) los dota de una alta visibilidad, pero cuyo impacto puede verse mermado, bien sincrónicamente por un aprecio que no sea proporcional a su divulgación (aunque aquí, como he señalado arriba, es preciso distinguir la valoración del público de la de la crítica), bien diacrónicamente, por carecer de huella duradera. Este último caso, no obstante, exige un factor de corrección, puesto que un alto nivel de impacto coetáneo puede haberse contrarrestado por una ulterior postergación, que no puede interferir con el análisis de la función desempeñada por ese autor en sincronía. Es el caso, por ejemplo, de fray Antonio de Guevara, tan influyente en su época como olvidado posteriormente, y a quien un estudio ponderado de la prosa áurea debe otorgar un relieve acorde al que le correspondía en sincronía. Algo semejante sucede

(Callon, Courtial y Penan, 1993: 47). Como índice de visibilidad, Price ha propuesto «el logaritmo de las citas recibidas por un autor», lo cual es un indicador más sutil que la mera cantidad total (vid. López López, 1996: 37). Por otro lado, el «factor de impacto» referido, no a un autor concreto, sino a una revista científica, es «a figure for the relative frequency with which the journal's 'average paper' has been cited. [...] The impact factor (IPF) is a better measure for the scientific importance of a journal than the total number of citations because it takes the total number of publications into account» (Egghe y Rousseau, 1990:
255). Puede verse una propuesta mucho más elaborada, pero lamentablemente desatendida, en Katz (1999: 6-8).

19. En este terreno sería de utilidad considerar el «modified approach to algorithmic historiography [...] used to investigate the changing influence of the work of Conrad Hal Waddington» por McCain (2008), todavía dentro del ámbito de la sociología de la ciencia (Waddington, fallecido en 1975, fue un paleontólogo y genetista escocés, pionero en biología del desarrollo y uno de los fundadores de la biología de sistemas), pero con una perspectiva diacrónica que podría ser útil a los fines aquí perseguidos. 
con Zorrilla, en quien se suman una elevada visibilidad, un altísimo índice de producción y un notable nivel coetáneo de impacto, pero que ha sido completamente relegado a los puestos bajos del canon en virtud del escaso aprecio que ha suscitado posteriormente, lo que, de suyo, es irrelevante para comprender la función de su obra en su contexto original de producción, difusión y recepción (o consumo, si se prefiere).

En resumen, partiendo del canon admitido (que implica el conocimiento de determinados autores, aunque no de modo acrítico), los criterios que, en la medida de lo posible, se habrían de tener en cuenta a la hora de seleccionar y jerarquizar a los autores, cuando ello sea pertinente, habrían de ser, por orden de importancia: la trascendencia histórica de su influjo (es decir, la medida en que sus propuestas estéticas, desde el nivel del estilo hasta el del género, han marcado la evolución de las prácticas literarias subsecuentes), su grado de representatividad de las corrientes dominantes en un período dado, sus innovaciones estéticas, sus niveles de visibilidad e impacto coetáneos (pues los que operan en diacronía corresponden al primer factor analizado) y su grado de productividad. La conjunción de un número mayor o menor de estas variables se traduciría, en consecuencia, en el principal determinante del tipo de atención prestada a un autor, aspecto muy importante en la organización de un temario no ya selectivo, sino necesariamente restrictivo, como sólo le cabe ser al que se adecue a las exigencias de una obra de síntesis, de un manual universitario o de una programación docente.

Por supuesto, no estoy postulando una reducción de la historia de la literatura a una pura sociología de base cuantitativa. En este terreno no se trata tanto de realizar estadísticas concretas (aunque serán muy bienvenidas en aquellos casos en que resulten factibles), cuanto de dotar del adecuado fundamento conceptual a categorías que ya en parte, aunque de forma tácita y asistemática, se están aplicando en la historiografía literaria. Por lo demás, las precedentes reflexiones no pretenden sustentar un canon con una validez absoluta; de hecho, ni siquiera pretenden validar la idea misma del canon como aspecto fundamental del estudio de la literatura. En efecto, todo canon adolece de un determinado grado de arbitrariedad y, desde una perspectiva global, el ideal de los estudios literarios sería poder abandonarlo y explicar todos los fenómenos de los que se ocupa, desde la propia existencia de la categoría cultural literatura hasta la menos conocida de sus manifestaciones concretas, es decir, la obra literaria de apariencia más insignificante. En tal caso, los factores empíricos aquí explorados no actuarían ya como elementos de criba, sino simplemente como rasgos caracterizadores que permiten situar a un autor u obra dados en unas determinadas coordenadas sociohistóricas, generadas por la intersección de sincronía y diacronía. Ahora bien, apelando a dos viejas y acertadas máximas, el aforismo hipocrático Ars longa, vita brevis, y el adagio evangélico Messis quidem multa, operarii autem pauci, esta utopía resulta inalcanzable, y si en la práctica de la investigación el proponer una nómina cerrada de autores u obras cae en el absurdo de ponerle puertas al 
campo, en ocasiones como las planteadas ya al inicio de estas líneas, en las cuales resulta inevitable realizar una selección en cuanto al número y establecer una jerarquía en cuanto a la atención prestada, criterios como los aquí propuestos pueden ayudar a que el canon no lo constituyan únicamente los apilados restos del naufragio del tiempo, sino que se conforme a partir de una propuesta justificada y puesta al servicio del fin último de la disciplina, que no es otro que explicar la literatura como conjunto y las producciones que individualmente la integran. 


\section{Bibliografía}

Alvar, Carlos; José-Carlos Mainer y Rosa Navarro (1997), Breve historia de la literatura española, Madrid, Alianza.

-, y José Manuel Lucía (eds.), Diccionario filológico de literatura medieval española, Madrid, Castalia, 2002 (Nueva Biblioteca de Erudición y Crítica, 21)

Bloom, Harold, El canon occidental: La escuela y los libros de todas las épocas, Barcelona, Anagrama, 1995.

Blecua, Alberto, y Francisco Rico, «La poesía de fray Luis: Entorno y códigos», Fray Luis de León, Poesía, ed. Antonio Ramajo Caño, Barcelona, Centro para la Edición de los Clásicos Españoles; Galaxia Gutenberg, 2006: IX-XVIII.

BlüHer, Karl Alfred, Séneca en España: Investigaciones sobre la recepción de Séneca en España desde el siglo XIII hasta el siglo XVII, trad. esp. rev., Madrid, Gredos, 1983.

Brown, Gerald G., Historia de la literatura española, 6/1: El siglo XX, 10. a ed. rev. por José Carlos Mainer, Barcelona, Ariel, 1983.

Callon, Michel; Jean-Pierre Courtial y Hervé Penan, La scientométrie, Paris, Presses Universitaires de France, 1993.

Canavaggio, Jean (dir.), Historia de la literatura española, vers. esp. dir. Rosa Navarro Durán, Barcelona, Ariel, 1994-1995, 6 vols.

Chомsкy, Noam, El conocimiento del lenguaje: Su naturaleza, origen y uso, Madrid, Alianza, 1989.

Coll-Vinent, Roberto, y Francisco J. Bernal Cruz, Curso de documentación, Madrid, Dossat, 1990.

Deyermond, Alan, "The lost literature of Medieval Spain: Excerpts from a tentative catalogue», La Corónica, 5 (1976-1977), 93-100.

- La literatura perdida de la Edad Media castellana: Catálogo y estudio, I: Épica y Romancero, Salamanca, Universidad, 1995.

-, (ed.), Keith Whinnom after Twenty Years: His Work and its Influence, Londres, Queen Mary, University of London (Papers of the Medieval Hispanic Research Seminar, 53), [en prensa].

Di Girolamo, Costanzo, Teoría critica de la literatura, Barcelona, Crítica, 1982.

Doležel, Lubomír, "A framework for the statistical analysis of style», Statistics and style, eds. Lubomír Doležel y R. W. Bailey, Nueva York; Londres, Elsevier, 1969: 10-35.

Egghe, Leo, y Ronald Rousseau, Introduction to Informetrics: Quantitative methods in Library, Documentation and Information Science, Amsterdam, Elsevier, 1990.

Escobar, Francisco Javier, "La forja del canon épico en la Academia de Juan de Mal Lara (con unos versos desconocidos de Fernando de Herrera)», Studia Aurea, 5 (2007). Editora Eugenia Fosalba. 12-04-2011. <http://www.studiaaurea.com/articulo.php? id=74 > 
Ferreras, Juan Ignacio (dir.), Historia crítica de la literatura hispánica, Madrid, Taurus, 1987-1992, 36 vols. previstos (32 publicados).

FisH, Stanley E., "How ordinary is ordinary language?», New Literary History, 5 (1973-1974), 41-54.

Frutos, Eugenio, Antropología Filosófica, ed. rev. al cuidado de A. Montaner, Zaragoza, Universidad, 1991.

Galván, Luis, El «Poema del Cid» en España, 1779-1936: Recepción, mediación, historia de la filología, Pamplona, EUNSA, 2001.

Gómez Redondo, Fernando, Historia de la prosa medieval castellana, Madrid, Cátedra, 1998-2007, 4 vols.

Guillén, Claudio, Teorías de la historia literaria, Madrid, Espasa-Calpe, 1989. Gullón, Ricardo, La invención del 98 y otros ensayos, Madrid, Gredos, 1969.

Grupo de Estudios Sobre Teatro Español (ed.), Horror y tragedia en el teatro del siglo de Oro: Actas del IV Coloquio del GESTE (Toulouse, 29-29 enero 1983), número monográfico de Criticón, 23 (1983).

Hermenegildo, Alfredo, La tragedia en el Renacimiento español, Barcelona, Planeta, 1973.

Jammes, Robert, «La literatura del Siglo de Oro a través de los manuales de historia y de comentario literarios", Actas del I Encuentro Franco-Alemán de Hispanistas (Mainz, 9-12.3.1989), eds. Ch. Strosezki, J.-F. Botrel y M. Tietz, Francfort del Meno, Vervuert, 1991: 214-221.

Jones, R. O. (dir.), A literary history of Spain, Londres, Ernest Benn, 19711972, 6 vols.

—, (dir.), Historia de la literatura española, Barcelona, Ariel, 1973-1984, 6 t. en 7 vols.

Katz, J. Sylvan, Bibliometric Indicators and the Social Sciences, informe realizado para el Economic and Social Research Council (United Kingdom), Sussex, 1999, accesible en línea. 12-04-2011. <http://www.sussex.ac.uk/Users/sylvank/pubs/ESRC.pd >

Lázaro Carreter, Fernando, Estudios de Poética: (La obra en sí), Madrid, Taurus, 1976.

López López, Pedro, Introducción a la bibliometría, Valencia, Promolibro, 1996.

LotKA, Alfred J., "The frequency distribution of scientific productivity», Journal of the Washington Academy of Sciences, 16, 12 (1926), 317-323.

Maestro, Jesús G., «Estado actual de la Teoría y Crítica de la Literatura en Europa", Contra los mitos y sofismas de la "teoría literaria" posmoderna, eds. Jesús G. Maestro e Inger Enkvist, Vigo, Academia del Hispanismo, 2010: $17-52$.

Mainer, José-Carlos, Historia y crítica de la literatura española, 6: Modernismo y 98, Barcelona, Crítica, 1980.

—, La Edad de Plata (1902-1939): Ensayo de interpretación de un proceso cultural, 2a ed., Madrid, Cátedra, 1983.

—, «Periodización literaria», Diccionario de literatura española e hispanoamerica- 
na, dir. Ricardo Gullón, Madrid, Alianza; Quinto Centenario, 1993, vol. I: $1261 a-1266 b$.

—, (ed.), Historia de la literatura española, Barcelona, Crítica, 2010-2011, 7 vols. (aparecidos 5).

Maltrás BARBA, Bruno, Los indicadores bibliométricos: Fundamentos y aplicación al análisis de la ciencia, Gijón, Trea, 2003.

McCaIn, Katherine W., «Assessing an author's influence using time series historiographic mapping: The oeuvre of Conrad Hal Waddington (1905-1975)", Journal of the American Society for Information Science and Technology, 59, 4 (February 2008), 510-525.

Montaner Frutos, Alberto, «El concepto de oralidad y su aplicación a la literatura española de los siglos XVI y Xviı", Criticón, 45 (1989), 183-192.

—, «Ínigo Balboa o la voz del narrador (con algunas consideraciones metacríticas)", Sobre héroes y libros: La obra narrativa y periodistica de A. Pérez-Reverte, eds. J. Belmonte Serrano y J. M. López de Abiada, Murcia, Nausícaä, 2003: 287-315.

—, «El epitafio épico del Cid», Actas del IX Congreso Internacional de la Asociación Hispánica de Literatura Medieval (A Coruña, 18-22 de septiembre de 2001), A Coruña, Universidade; Toxosoutos, 2005, vol. III: 193-203.

—, «En defensa del sentido literal: De la interpretación a la explicación en el estudio de la literatura", Contra los mitos y sofismas de la "teoría literaria" posmoderna, eds. Jesús G. Maestro e Inger Enkvist, Vigo, Academia del Hispanismo, 2010: 159-215.

Moreno, Víctor, De brumas y de veras: La crítica literaria en los periódicos, Pamplona, Pamelia, 1994.

MuKAŘovskÝ, Jan, Escritos de estética y semiótica del arte, ed. J. Llovet, Barcelona, Gustavo Gili, 1977.

PÁniker, Salvador, «Novedades discográficas», El País, (6 de diciembre de 2006), 13-14.

Pozuelo Yvancos, José María, y Rosa María Aradra Sánchez, Teoría del canon y literatura española, Madrid, Cátedra, 2000.

Romero Tobar, Leonardo, Panorama crítico del romanticismo español, Madrid, Castalia, 1994.

—, La literatura en su historia, Madrid, Arco Libros, 2006.

Rey Hazas, Antonio, "Los comendadores de Córdoba en el proceso de elaboración de la tragicomedia barroca», La Comedia: Seminario Hispano-Francés organizado por la Casa de Velázquez: Madrid, Diciembre 1991-Junio 1992, ed. Jean Canavaggio, Madrid, Casa de Velázquez, 1995: 303-319.

Rubio Cremades, Enrique, Panorama crítico de la novela realista-naturalista española, Madrid, Castalia, 2001.

Ruiz Baños, Rosario, «Ley de Lotka», Cognosfera (Universidad de Granada). Editores Rafael Bailón Moreno y Rosario Ruiz Baños. 10-04-2011, <http:// www.ugr.es/ rruizb/cognosfera/sala_de_estudio/>. 
Rodríguez Moñ Ino, Antonio, Construcción critica y realidad histórica en la poesía española de los siglos XVI y XVII, 2a ed., Madrid, Castalia, 1968.

Sánchez Escribano, Federico, y Alberto Porqueras Mayo, Preceptiva dramática española del Renacimiento y el Barroco, Madrid, Gredos, 1971.

Schmidt, Siegfried J., Fundamentos de la ciencia empirica de la literatura: El ámbito de actuación social Literatura, trad. F. Chico, Madrid, Taurus, 1991.

Sirera, Josep Lluis, «Los trágicos valencianos», La génesis de la teatralidad barroca, Valencia, Universidad, 1981: 67-91.

—, «Rey de Artieda y Virués: la tragedia valenciana del Quinientos», Teatros y prácticas escénicas, II: La comedia, ed. Juan Oleza, Londres, Tamesis; Valencia, Institución «Alfonso el Magnánimo», 1986: 69-101.

Sito Alba, Manuel, «El teatro en el siglo Xvi (desde finales de la Edad Media a comienzos del siglo XVII)", Historia del teatro en España, ed. Jose María Díez Borque, Madrid, Taurus, 1984, vol. I: 155-471.

SMITH, Colin, "On the 'lost literature' of Medieval Spain», "Guillaume d'Orange» and the "Chanson de Geste»: Essays presented to Duncan McMillan in celebration of his seventieth birthday, Reading, Societé Rencesvals, 1984: 137-150.

TACCA, Óscar, «Historia de la literatura», Métodos de estudio de la obra literaria, ed. José María Díez Borque, Madrid, Taurus, 1985: 210-216.

Terrada, María Luz, y Rafael Peris Bonet, Lecciones de documentación médica, Valencia, Departamento de Historia de la Ciencia y Documentación, Universidad, 1988.

Urbano, Cristóbal, et al., «Análisis bibliométrico de la bibliografía citada en estudios de Filología Española», Revista Española de Documentación Cientifica, 28, 4 (2005), 439-461.

URía, Isabel, Panorama crítico del «mester de clerecía», Madrid, Castalia, 2000.

Vega Reñón, Luis, y Paula Olmos Gómez, Compendio de lógica, argumentación y retórica, Madrid, Trotta, 2011.

WAGENSBERG, Jorge, A más cómo, menos por qué: 747 reflexiones con la intención de comprender lo fundamental, lo natural y lo cultural, Barcelona, Círculo de Lectores, 2006.

Wardropper, Bruce W., «Juan de la Cueva y el drama histórico», Nueva Revista de Filología Hispánica, 9 (1955), 149-156.

Whinnom, Keith, Spanish literary historiography: three forms of distortion, Exeter, Exeter University Press, 1967. 